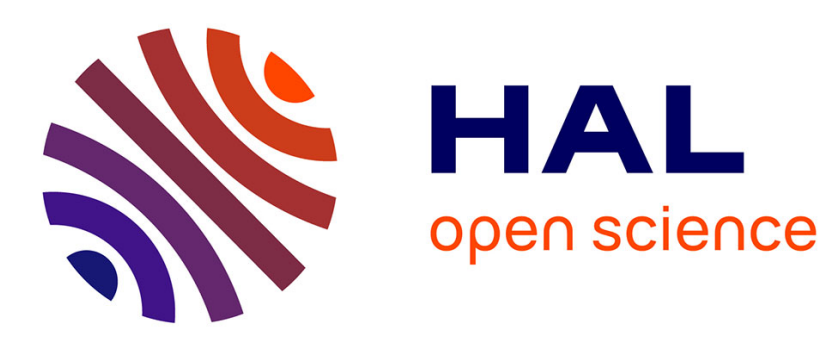

\title{
Precision Measurements of Vehicle Crashworthiness by Means of a Large Hopkinson Bar
}

\author{
C. Albertini, E. Cadoni, K. Labibes
}

\section{To cite this version:}

C. Albertini, E. Cadoni, K. Labibes. Precision Measurements of Vehicle Crashworthiness by Means of a Large Hopkinson Bar. Journal de Physique IV Proceedings, 1997, 07 (C3), pp.C3-79-C3-84. 10.1051/jp4:1997316 . jpa-00255449

HAL Id: jpa-00255449

https://hal.science/jpa-00255449

Submitted on 1 Jan 1997

HAL is a multi-disciplinary open access archive for the deposit and dissemination of scientific research documents, whether they are published or not. The documents may come from teaching and research institutions in France or abroad, or from public or private research centers.
L'archive ouverte pluridisciplinaire HAL, est destinée au dépôt et à la diffusion de documents scientifiques de niveau recherche, publiés ou non, émanant des établissements d'enseignement et de recherche français ou étrangers, des laboratoires publics ou privés. 


\title{
Precision Measurements of Vehicle Crashworthiness by Means of a Large Hopkinson Bar
}

C. Albertini, E. Cadoni and K. Labibes

European Commission, Joint Research Centre, Institute for Systems, Informatics and Safety, TP 480, 21020 Ispra (Va), Italy

\begin{abstract}
The main results of two impact testing campaigns of automotive longitudinal beams in mild steel and aluminium performed by means of the large Hopkinson bar of the Joint Research Centre Ispra site are reported. The need of precision crash tests for the aim of calibration of industrial impact rigs and validation of FE code is discussed.
\end{abstract}

Résumé. Deux campagnes de tests sur des modèles de longerons de voitures en acier et en aluminium sont presentés. Les essais ont ete réalisés sur la grande barre de Hopkinson du Centre Commun de Recherche d'Ispra. La calibration des moyens d'essais industriels sera discutée ainsi que la validation des codes de calcul.

\section{INTRODUCTION}

A large Dynamic Testing Facility (LDTF) [1] was constructed in 1982 at the J.R.C Ispra site of the European Communities for material and component impact testing under the Nuclear Fission Safety programme (EUR Patent 007740 al). The LDTF is now included in the European Community "Measurement and Testing" programme, chapter "Car Safety". The principal target of the LDTF-Car Safety programme is that of developing a precision crash testing method with the aim of helping the automotive industry:

- to perform accurate measurements of energy absorption capability of car body components and subassemblies dedicated to mitigate crash effects by transforming car kinetic energy into material deformation energy,

- to calibrate the impact rigs active in the industrial laboratories,

- to validate the analysis predictions of finite elements codes in order to implement them with efficiency in the production process.

The development of a precision crash testing method must take into account that the crashing of vehicles together or against barriers and other obstacles is a complex event of some milliseconds duration $(\sim 100$ $\mathrm{ms}$ ) which can be approximately subdivided into :

- a first phase governed by elasto-plastic stress wave propagation through the vehicle structures,

- a second phase governed by inertial effects and interaction between the mechanical components due to the large crash displacements.

The physical phenomena which characterise the vehicle structure response during the two phases of a crash are strongly dependent both on the mechanical properties of materials under dynamic loading and on the geometry of vehicle structures.

The first phase of the crash where elastic stress waves propagate through the vehicle structures at a speed of about $5000 \mathrm{~m} / \mathrm{s}$, has a duration of the order of a few milliseconds ( $4 \mathrm{~ms}$ or less) and is characterised by particle acceleration in which the amplitude mainly depends on the initial yielding of materials and structures; high yielding stress gives rise to high particle acceleration which might be dangerous for the human body. Immediately after yielding, plastic stress waves propagate at a speed which 
is dependent of the slope of the material stress-strain curves; sharp slopes give rise to higher plastic stress wave speed. In any case plastic stress wave speed is about one order of magnitude less than elastic stress wave speed.

During the second phase the interaction between the mechanical components (e.g. between engine and body structures) might give rise to further stress wave effects. Therefore the crashworthiness optimisation of vehicles requires the development of crash testing techniques based on wave propagation principles which allow the precise measurement of dynamic loads and displacements.

It is well known that the classical split Hopkinson bar [2] has been developed for the study of the mechanical properties of materials at high strain rate by strictly controlling and measuring the incident, reflected and transmitted stress wave acting on a specimen of gauge length short enough that load equilibrium at its end can be assumed. Herein it will be shown the extension of the Hopkinson bar method to the measurement of mechanical characteristics of longitudinal beams submitted to a crash test. It will be referred about two main testing campaigns:

- the first campaign in collaboration with FIAT Research Centre concerned the testing of double hat steel longitudinal beams joined by adhesive and spot welding,

- a second campaign concerned the testing benchmark of aluminium longitudinal beams performed in collaboration with 13 European crash test laboratories using the conventional impact rigs.

\section{THE LARGE HOPKINSON BAR METHOD FOR PRECISION IMPACT TESTING OF AUTOMOTIVE COMPONENTS}

The basic configuration of the Hopkinson bar developed at JRC Ispra consists [3, 4](figure 1) of a prestressed bar for energy storage, an incident bar, an output bar and a specimen inserted between the two last bars. On the release of the blocking device an incident tension pulse $\varepsilon_{i}$ propagates to the specimen where one part of the pulse is reflected $\varepsilon_{\mathrm{r}}$ and one part is transmitted $\varepsilon_{\mathrm{t}}$

BAR 1

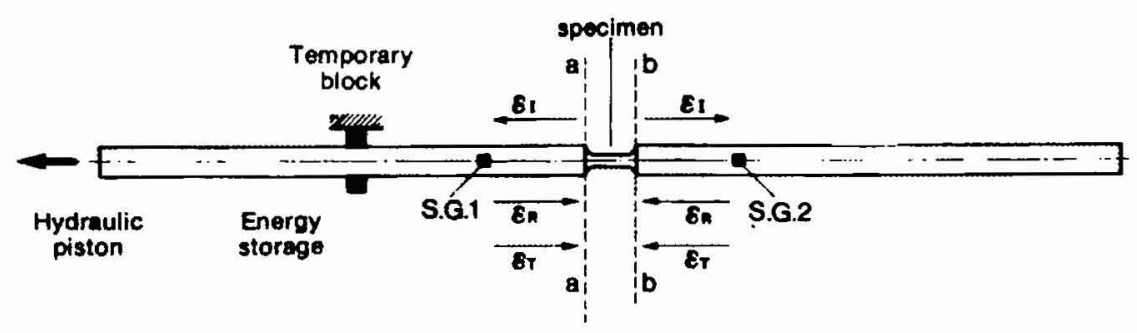

Figure 1: Basic configuration of the JRC tension Hopkinson's bar.

The length of the incident bar and the output bar are such that the reflections of the waves from the remote bar ends do not reach the specimen before the test is completed, allowing a clear record of the incident, reflected and transmitted pulses $\varepsilon_{\mathrm{i}}, \varepsilon_{\mathrm{r}}$ and $\varepsilon_{\mathrm{t}}$, by means of two strain gauge stations on the incident and output bars. Therefore by controlling the amplitude of the prestress of the bar between blocking device and hydraulic actuator and the length of the incident and output bar it is possible to exert a strict control over the amplitude and duration of the pulses $\varepsilon_{\mathrm{i}}, \varepsilon_{\mathrm{r}}$ and $\varepsilon_{\mathrm{i}}$.

Consider as an example a thin sheet metal box of length $500 \mathrm{~mm}$ and of square section of $100 \mathrm{~mm}$ side and $1 \mathrm{~mm}$ thickness, which must be shortened by $250 \mathrm{~mm}$ at a constant speed chosen between $5.5 \mathrm{~m} / \mathrm{s}$ $(20 \mathrm{~km} / \mathrm{h})$ and $41.6 \mathrm{~m} / \mathrm{s}(150 \mathrm{~km} / \mathrm{h})$. The compression pulse to accomplish the required shortening of the box in the above mentioned speed range must be at least $45 \mathrm{~ms}$ duration at the lowest speed and $6 \mathrm{~ms}$ at the highest speed. These test conditions were obtained by using a large Hopkinson bar having the basic 
configuration of figure 1 , installed in the LDTF and modified as shown in figure 2 for testing under compression. The large Hopkinson bar practically works as follows:

The cable of $100 \mathrm{~m}$ length is prestressed by the hydraulic actuator and the load is sustained by the explosive bolt. When the explosive bolt is actuated, a compression pulse is applied to the thin sheet metal box and measured in the input and output bar. The rise time of the applied pulse can be controlled in order to simulate either soft or hard impact. In terms of energy applied to the specimen, the LDTF tests can be compared with a conventional test, which uses a mass launched against the box , by equating the elastic potential energy stored in the cable to the kinetic energy of a mass $M$ attached to the cable end once the exploding bolt has been broken:

$$
\frac{1}{2} \mathrm{~F} \cdot \Delta \mathrm{L}=\frac{1}{2} \mathrm{MV}^{2}
$$

Where $\mathrm{F}$ is the load of the pretensioned cable ; $\Delta \mathrm{L}$ is the elongation of the cable and $\mathrm{V}$ the speed of the mass $M$.

The speed remains constant during the whole test. The assumption of small transverse dimensions of the input and output bars $(\mathrm{cm})$ in comparison with the pulse wavelength $(100 \mathrm{~m})$ is valid. Therefore the wave propagation in the input and output bars of the LDTF can be analysed by one dimensional wave propagation theory. The loads measured at the same time at the input and the output ends of the box are different, as shown in figure 3 , because the applied stress wave needs a travelling time of about $100 \mu$ s to cover the distance between the ends of the box $(500 \mathrm{~mm})$. This fact gives rise to a load gradient along the box with an initial peak load at the input end which causes the initiation of the yielding-folding process at the input end.

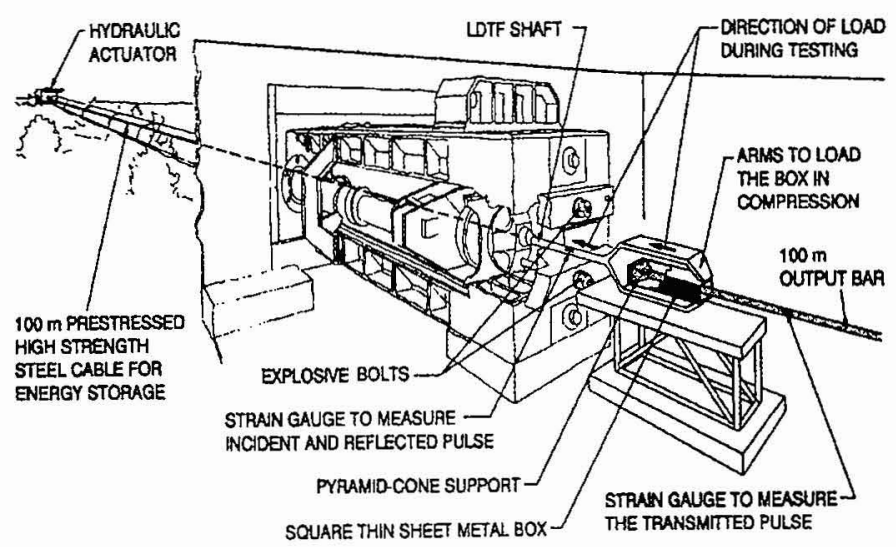

Figure 2: LDTF modified for Hopkinson's bar compression tests

\section{LOAD SHORTENING CHARACTERISTICS OF AUTOMOTIVE LONGITUDINAL BEAMS BY LARGE HOPKINSON'S BAR MEASUREMENTS.}

Double hat automotive longitudinal beams in steel sheet of $1.2 \mathrm{~mm}$ thickness were constructed by Centro Ricerche Fiat by spot welding and bonding

Two different steels have been considered:

- FePO4 high formability mild steel normally adopted for manufacturing of car body components,

- FEE315 high deformability and higher strength steel as alternative material.

The longitudinal beams were tested in compression using the LDTF large Hopkinson bar at a speed of $11 \mathrm{~m} / \mathrm{s}$ maintained constant during the whole test. The incident pulse $\varepsilon_{\mathrm{i}}$, the reflected pulse $\varepsilon_{\mathrm{r}}$ and the 
transmitted pulse $\varepsilon_{\mathrm{t}}$ were measured at the two strain gauge stations place on the input and output bars (figure 2). A typical test record is shown in figure 3; the pulses are seen without any filtering process, showing that the system allows a good resolution of loading and response waves.

The oscillations shown on the reflected $\varepsilon_{\mathrm{r}}$ and transmitted $\varepsilon_{\mathrm{t}}$ pulses correspond to fold formation during deformation of the box, as verified by fast film record of the whole test. Detailed results of this research are reported in [5] while here will be mentioned the relevant results concerning the testing method.

Due to the length of the longitudinal beam $(500 \mathrm{~mm})$ and the stress wave propagation into them, a load gradient builds up along the beams as shown in figure 3 which is relatively large at the beginning of the test and tends to disappear with duration of the test due to the number of wave reflections. This fact shows the importance of using a crash testing method taking in to account wave propagation in order to make an accurate measurement of the load-displacement characteristics under impact loading of passive safety dedicated automotive components and for a deeper understanding of the folding mechanism of thin sheet metal boxes.

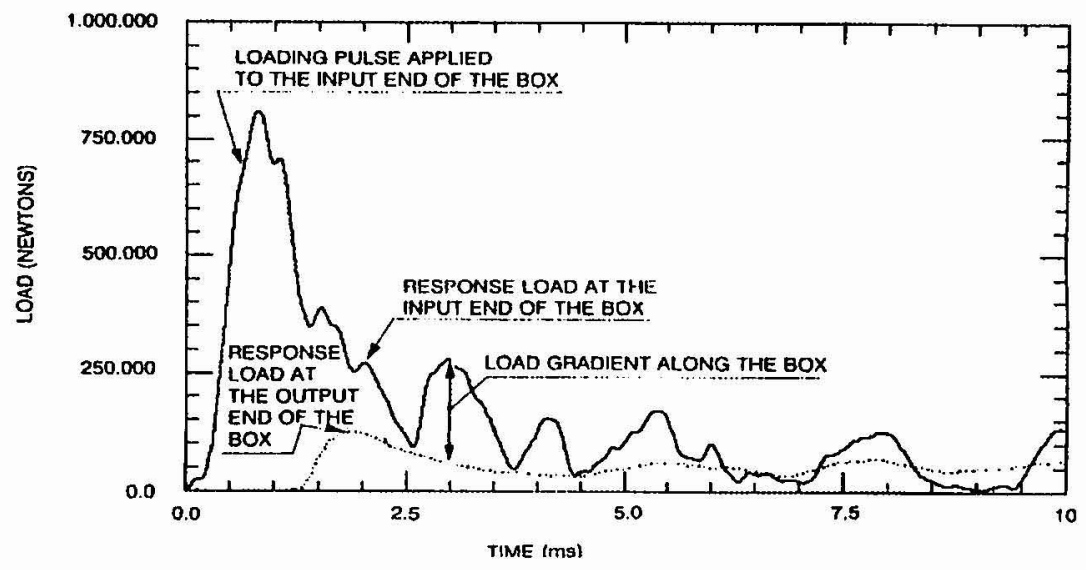

Figure 3: Load gradient along the box

The load displacement characteristics of the double hat mild steel longitudinal beams are shown in figure 4 . It can be observed that the higher energy absorption is obtained with high strength steel FEE315 longitudinal beams. It is also shown in figure 4 the presence of an important load peak which can be dangerous because it might induce to high deceleration on the car passengers. It emphasises the importance of the measurement of the first load peak which is possible with the Hopkinson bar measurement as it will be shown below.

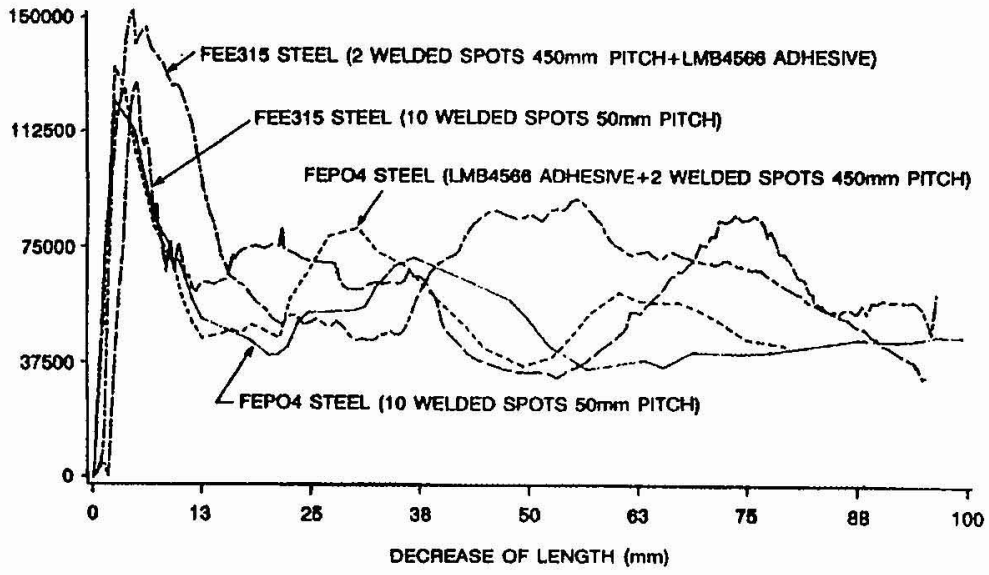

Figure 4: Load vs. shortening curves of different longitudinal beams. 


\section{BENCHMARK ON AUTOMOTIVE LONGITUDINAL BEAMS CRASH TESTING}

In the frame of the Human Capital and Mobility programme of the European Union, the Large Hopkinson bar installed in the LDTF has been supported to perform a benchmark exercise between 14 European crash test laboratories in order to compare the measurements of load-displacement characteristics of the same aluminium alloy longitudinal beams tested with the different impact rigs of the laboratories.

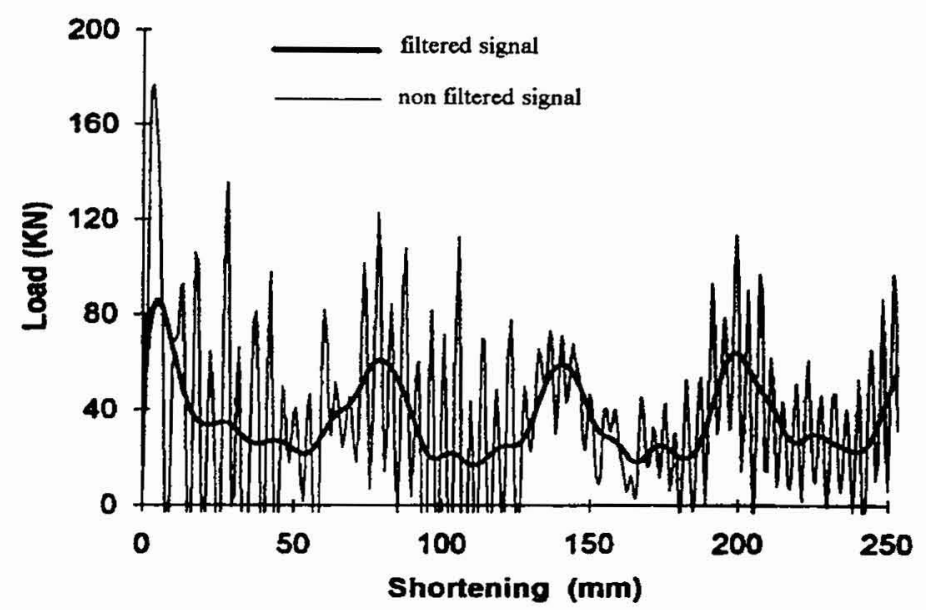

Figure 5: Load vs. shortening curve obtained on classical impact rig

The detailed results of the benchmark exercise, which resorted from an idea of Professor $T$. Wierzbicki of Massachusetts Institute of Technology, are reported in [6]. The main achievements are reported in this paper. Figure 5 and 6 shows respectively the records from a drop-hammer impact rig test and the original signal from the LDTF large Hopkinson bar test; it is possible to observe that the large Hopkinson bar record is free from the oscillations which must be filtered in the case of the drop hammer rig record. It is shown by the LDTF test (fig.6) that for aluminium longitudinal beams there is no prevalence of the first load peak with respect to the successive ones. This can be explained by the strain rate insensitivity of the material. At the contrary the other impact rigs show that the first peak load is higher than the others.

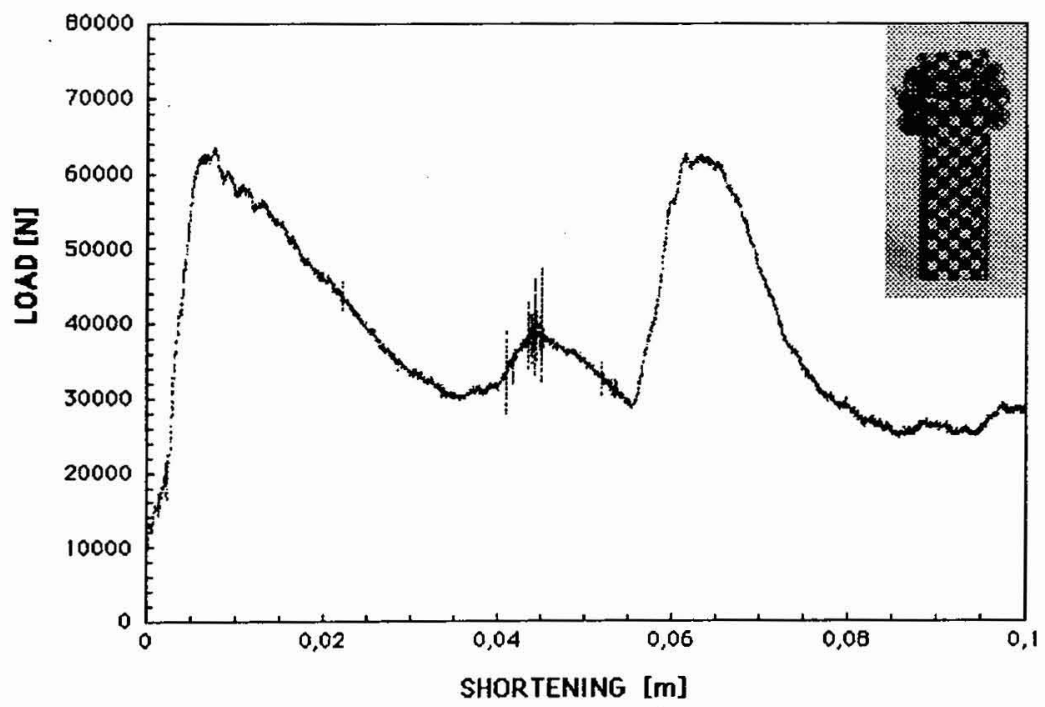

Figure 6: Load vs. shortening curve obtained on the LDTF 
It was shown in this benchmark that there was a large discrepancy between the parameters of the loaddisplacement characteristics measured in the different laboratories and the LDTF, as shown in table 1 From this comparison it results that filtering is not enough to eliminate the uncertainties of drop-weight impact rigs. Therefore, benchmark exercises (like that described here) are needed on longitudinal beams of complex mechanical response (like that of mild steel) in order to calibrate impact rigs for dynamic crash test.

table 1:

\begin{tabular}{|c|c|c|c|c|c|c|c|c|c|c|c|c|c|}
\hline $\begin{array}{c}\mathrm{V}_{0} \\
\mathrm{Km} / \mathrm{h}\end{array}$ & Lab N. & LDTF & 2 & 3 & 4 & 5 & 6 & 7 & 8 & 9 & 10 & 12 & 14 \\
\hline 30 & $\mathrm{dlp} \%$ & - & +72 & +160 & +65 & +133 & +145 & +99 & +8 & +27 & +75 & +30 & +16 \\
\cline { 2 - 13 } & $\mathrm{dlpm}$ & - & -9 & -9 & -20 & -15 & -35 & -17 & -20 & -27 & -19 & -27 & -25 \\
\hline \multirow{2}{*}{50} & $\mathrm{dlp} \%$ & - & +130 & +770 & - & +190 & - & +109 & - & - & +90 & - & +8 \\
\cline { 2 - 12 } & $\mathrm{dlpm}$ & - & -4 & +34 & - & -4 & - & -6 & - & - & -16 & - & -22 \\
\hline
\end{tabular}

Key: dlp : Spread of the first peak load around the LDTF value (no filter)

$\mathrm{d} 1 \mathrm{pm}$ : Spread of the mean load Pm around the LDTF value

$\mathrm{V}_{0}$ : test speed

\section{CONCLUSION}

It has been shown that the Hopkinson's bar method allows the correct measurement of the loaddisplacement characteristics and therefore of the energy absorption capability of the thin sheet metal structures used as energy absorbing system to limit injuries to occupants in case of car collision.

The performance of the proposed testing method appears to be more accurate than all existing testing techniques because it is possible to control the stress wave propagation caused by impact loading. This accuracy is particularly evident in the measurement of the initial peak crushing strength and of the first deformation phases of the structures. The control of stress wave propagation along the thin sheet metal structures is also of basic importance for understanding the folding mechanism under impact loading. The same technique can be extended to subassemblies of increasing complexity up to the whole car structure and be a reference for the validation of finite element code results.

The large Hopkinson's bar experiments on thin sheet metal structures could also be used for the calibration of the testing techniques normally used in industrial laboratories.

\section{References}

[1] C. Albertini, P. M. Boone and M. Montagnani. "Development of the Hopkinson bar for testing Large Specimens in Tension" Journal de Physique, Colloque C5, supplement N. 8, tome 46, august (1985).

[2] R. M. Davies, "Critical study of the Hopkinson's pressure bar", Phil. trans. Roy. Soc. London Ser., A.240-375.

[3] C. Albertini, M. Montagnani, Testing techniques based on the split Hopkinson's bar, Inst. of Physics, Conf. Ser. N. 21, London, pp. 22-31.

[4] C. Albertini, M. Montagnani, “Dynamic material properties of several steels for fast breeder reactor safety analysis, EUR report $5787 \mathrm{EN},(1977)$.

[5] C. Albertini, A. Blarasin T. Giunti, G. Molina. "A new approach to crashworthiness studies on thin sheet metal structures using the large Hopkinson bar method" EUR technical note N. I.92.133.

[6] C. Albertini, E. H. Hanefi, T. Wierzbicki . "Calibration of impact rigs for dynamic crash testing" Report EUR 16347 EN 